\section{GW23-e0968 RESEARCH ON THE RELEVANCE AND CLINICAL SIGNIFICANCE OF THE 24 H DYNAMIC BLOOD PRESSURE MONITOR AND LEFT VENTRICULAR HYPERTROPHY IN HYPERTENSION}

doi:10.1136/heartjnl-2012-302920r.4

Wei Xiao-jun, Wei Xiao-jun. Department of Cardiology, Affiliated Hospital of Gannan Medical College, GanZhou, JiangXi 341000

Objectives To investigate the relevance and clinical significance of $24 \mathrm{~h}$ dynamic blood pressure monitor and left ventricular hypertrophy in hypertension.

Methods From January 2008 to January 2010, 155 patients (76 males and 79 females) with hypertension were investigated. There were 64 examples of grade 1 hypertension, 56 examples of grade 2 hypertension and 35 examples of grade 3 hypertension. Average arterial pressure (SBP, DBP), diurnal systolic pressure (dSBP, nSBP) and diurnal diastolic pressure ( $\mathrm{dDBP}, \mathrm{nDBP})$ level were collected by dynamic blood pressure monitor. End-diastolic diameter of left ventricle (LVID), end-diastolic left ventricular posterior wall thickness (LVPW), diastolic interventricular septum thickness (IVS) and left ventricular mass index (LVMI) were investigated by echocardiogram.

Results Blood pressure circadian rhythm disappeared (non-scoop type) and left ventricular hypertrophy occurred (LVMI, 138.96 $\pm 10.99 \mathrm{~mm}$ ) in 48 examples of grade 2 hypertension and 35 examples of grade 3 hypertension. The day and night rule (scoop type) was reserved without LVH (LVMI, 116.13 $\pm 4.95 \mathrm{~mm}$ ) in 64 examples of grade 1 hypertension and eight examples of grade 2 hypertension. The night systolic pressure, the night diastolic pressure and the average arterial pressure average value in hypertension with left ventricular hypertrophy were obviously higher than those without LVH $(p<0.01)$. But the day systolic pressures and the day diastolic pressure lever were not obvious difference between two groups $(\mathrm{p}>0.05)$

Conclusions The level of night systolic pressure, night diastolic pressure and average arterial pressure are closely related to left ventricular hypertrophy and non-scoop hypertension is easier to be left ventricular hypertrophy compared with the scoop hypertension. 